\title{
Problematic Internet Use- An introduction and current status in Nepal
}

\author{
Shakya $\mathbf{R}^{1}$, Sharma $\mathbf{P}^{2}$
}

1.Associate Professor, Department of Psychiatry, Patan Academy Of Health Sciences, Kathmandu, Nepal 2. Lecturer, Department of Psychiatry, Patan Academy Of Health Sciences, Kathmandu, Nepal

E-mail *Corresponding author: rabishakya@pahs.edu.np

\begin{abstract}
Life has become easier with the advent of internet; however excessive use of internet has created a lot of problems.

Problematic internet use has been regarded as a separate clinical entity and the researches on its various aspect is on a rise all around the globe in the last decade. This condition though fairly common in Asian context too; has not seen much of recognition in clinical and research setting in Nepal. Review of the major databases has yielded four original studies in Nepal. These cross sectional studies have made an attempt to highlight the prevalence, comorbidities and mediators to some extent. However, this doesn't seem to be enough as compared to the literature base needed in the current scenario. Hence, we emphasize on creating awareness among public, early recognition in clinics by clinicians and further research in tertiary health care levels by researchers about this recently rising public health issue of Problematic Internet Use.
\end{abstract}

\section{Keywords: Problematic Internet Use, Internet Addiction, Nepal}

\section{INTRODUCTION}

Over the last two decades, the global internet using population has grown to almost 2.5 billion. ${ }^{1}$ Internet use is nearly ubiquitous among adolescents and young adults; current US data suggests that $93 \%$ of adolescents and adults between the ages of 12 and 29 years are active online frequently. ${ }^{2}$ Despite having potential uses excessive internet use has also become a significant mental health concern. With the growth in technology and internet use, the concept of problematic internet use or internet addiction has also gained attention in the popular media and among researchers. ${ }^{3}$ Problematic Internet addiction or excessive Internet use is characterized by excessive or poorly controlled preoccupations, urges, or behaviors regarding computer use and internet access that lead to impairment or distress. ${ }^{4}$.For the past two decades there has been increasing research efforts on internet addiction. This have led the American Psychiatric Association (APA) to include Internet Gaming Disorder in the appendix of the updated version of the Diagnostic and Statistical Manual for Mental Disorders (DSM-5) in 2013 as condition that requires further research before it can be accepted for inclusion in the main manual. ${ }^{5}$ This has resulted in researchers commencing efforts to reach an international consensus for assessing Internet Gaming Disorder using the new DSM-5 approach based on international expert.Currently, both diagnosis and research of internet-use disorders appears rather broad. ${ }^{6}$ Many authors argue about the nosological differences between addictions tothe internet i.e. generalized internet use, and addictions onthe internet like gambling, video gaming, sex and shopping ${ }^{7}$. In the context of our country Nepal, we have also been 
getting cases with significant dysfunctions due to excessive internet use.

Excessive Internet Use has been described by four main components: (a) Internet overuse and loss of sense of time, (b) withdrawal symptoms; tension or depression when use is limited, (c) tolerance; e.g., need for more time online and (d) negative effects on social functioning. The "Problematic Internet use", is broadly defined as: a) maladaptive preoccupation with Internet use, experienced as irresistible use for periods of time longer than intended; b) significant distress or impairment resulting from the behavior; and c) the absence of other Axis I pathology that might explain the behavior, such as mania or hypomania. ${ }^{8}$ This entity is known in different names like Computer Addiction, Internet Addiction (Disorder), and Pathological Internet Use. ${ }^{891011}$ In this article we would talk about all the phenomenon as a single rubric of Problematic Internet Use (PIU).

\section{HISTORICAL PERSPECTIVE:}

The need of establishing this as a separate clinical entity and efforts towards developing a diagnostic criterion began in the 1990s. The first scientific description of a young man who developed severe psychosocial problems due to his excessive Internet use was done by Young (1996). ${ }^{12}$ While Internet addiction was not recognized in previous versions of DSM, Goldberg,a pioneer in the field, developed Internet Addictive Disorder (IAD) scale by adapting DSM-IV and provided several diagnostic criteria, includingtwo commonly used statements often seen in Internet addiction research: "hoping to increase time on the network" and "dreaming about the network." After that many scales and criteria were given by different researchers in this regard.Two initial approaches to Problematic Internet Use were based upon existing DSM-IV disorders: substance abuse/dependency and pathologic gambling. ${ }^{13}$ This early work was accompanied by the introduction of three conceptual approaches.

a. PIU was broadly described as general behavioral addiction. ${ }^{14}$

b. A cognitive-behavioral model of PIU drew attention to the impact of an individual's thoughts on their development of problematic behaviors, and separated PIU into "generalized" PIU, or multidimensional overuse of the internet, and "specific" PIU. ${ }^{15}$ Specific PIU was described as dependence on a specific function of the internet.

c. Another model proposed that PIU should be more widely classified as an impulse control disorder with criteria defined as: a) maladaptive preoccupation with internet use characterized by either irresistible use, or use that is excessive and longer than planned; b) clinically significant distress or impairment; and, c) an absence of other, explaining, Axis I disorders. ${ }^{8}$

These differences in the conceptual approach towards PIU have influenced the various instruments and rating scales that have been developed to evaluate PIU.

\section{MEASUREMENT:}

Due to the lack of consensus on diagnostic criteria and the dearth of large epidemiological studies, the prevalence of problematic internet use varied widely. At present, there are at least 13 instruments designed to measure PIU. Several instruments were adapted from the DSM-IV substance abuse and dependency criteria, like the Internet Addiction Disorder Diagnostic Criteria and the Internet-Related Addictive Behavior Inventory. ${ }^{16}$ There are others which are based on the DSM-IV criteria for pathological gambling, including the Young Diagnostic Questionnaire 14 and Young Internet Addiction Test (IAT), Chen Internet Addiction Scale, and Problematic Internet Usage Questionnaire. Other instruments are based on the PIU behavioral addiction model, like the Compulsive Internet Use Scale or the Griffith Addiction Components Criteria. Some other instruments are based on the Davis cognitive-behavioral model of PIU, including the Online Cognition Scale (OCS) and the Generalized Problematic Internet Use Scale (GPIUS). ${ }^{17}$ However, none of the scales used world wide have been validated in the population of Nepal.

\section{PREVALENCE:}

Most of the studies on problematic internet use have been focused in youth. In the United States, an online survey of 17,251 responders found that $6 \%$ of the survey population met the criteria for Internet addiction. ${ }^{18}$ The rate of problematic Internet use in Italian adolescent was 5.4\%.$^{19}$ Using the Pathological Internet Use (PIU) scale in British students, 18.3\% were considered to be pathological Internet users. ${ }^{20}$ In studies ofEuropean adolescents, the estimates of problematic internet use are reported as between 19\%, Middle Eastern prevalence estimates are between $1-12 \%$ and Asian prevalence estimates are reported between $2-18 \% .{ }^{21}$ Given these high rates of internet use, "problematic internet use" is a growing concern especially amongst adolescents and young adults. ${ }^{21}$ The heterogeneity in findings in prevalence in different cultural groups reflect a need of further exploration whether it is due to cross-cultural 
differences or the disparities in the operational definitions of "problematic internet use". Internet addiction has become a serious behavioral health problem in Asia. The reported higher prevalence rates in China has demonstrated it to be a serious problem in China because of which the country has acknowledged Internet addiction as official disorder in 2008. ${ }^{22}$ The Asian Adolescent Risk Behavior Survey (AARBS) compared the prevalence of Internet behaviors and addiction in adolescents in six Asian countries. A total of 5,366 adolescents aged 12-18 years were recruited from six Asian countries: China, Hong Kong, Japan, South Korea, Malaysia, and the Philippines. Participants completed a structured questionnaire on their Internet use in the 2012-2013 school years. Internet addiction was assessed using the Internet Addiction Test (IAT) and the Revised Chen Internet Addiction Scale (CIAS-R). The variations in Internet behaviors and addiction across countries were examined. The overall prevalence of smartphone ownership was reported to be $62 \%$, ranging from $41 \%$ in China to $84 \%$ in South Korea. Moreover, participation in online gaming ranged from $11 \%$ in China to $39 \%$ in Japan. Hong Kong had the highest number of adolescents reporting daily or above Internet use $(68 \%)$. Internet addiction was reported to be highest in the Philippines, according to both the IAT (5\%) and the CIAS-R $(21 \%){ }^{23}$ The main difficulty with these studies is that they use vague terms to describe levels of Internet use, such as "borderline," "excessive," "at risk," and "addictive," which arenot operationally defined or clinically validated. ${ }^{4}$

\section{IMPACT:}

Several studies globally, and numerous anecdotal media reports, suggest possible links between overuse of the internet by adolescents and young adults and negative health consequences such as depression, ADHD, excessive daytime sleepiness, problematic alcohol use, or injury. Internet addiction has also been associated with negative academic consequences such as missed classes, lower grades and academic dismissal. ${ }^{17}$ Psychological and environmental factors in the lives of college students may leave them disproportionately vulnerable to internet addiction. Despite the potential benefits, numerous problems such as exposure to inappropriate images and content, absence of privacy and addiction have been reported as a result of this increasing usage of internet. ${ }^{24}$ Developmental stressors coupled with free access to internet services may contribute to college student's vulnerability to problematic internet use. $^{25}$ It is still unknown whether Internet addiction and these comorbid disorders could be explained by shared risk factors or considered as secondary disorders.

\section{STUDIES IN NEPAL:}

The systematic search of literature in PubMed, Google Scholar andPsycINFO using the keywords ("excessive Internet use" or "problematic Internet use" or "pathological Internet use" or "Internet addiction" or "excessive computer use" or "Internet gaming" or "computer gaming" or "Internet gaming addiction" of "Internet gaming disorder" AND "Nepal"lead to only four articles in the form of original research (Table 1).

All the studies conducted in Nepal are crosssectional and the sample size ranged from 130 to 984. They were all conducted in the college going youths. Two studies ${ }^{2627}$ have seen just the cross sectional prevalence in a selected group of students using Young's internet addiction test and found an incidence comparable to each other. The severe addiction prevalence in the two groups were $3.07 \%$ and $1.3 \%$ respectively. Similarly, a study by Jha et al. ${ }^{28}$ has used a self administered questionnaire having multiple sets of questions and the study is descriptive. Though a pre-study sample was taken and tested in ten students (not included in the final study), the questionnaire isnot standardized. The study only looked at the different variables for Facebook use not in the overall problematic internet use. Among all the studies conducted in Nepal, the study by Bhandari et al. ${ }^{29}$ is methodologically superior. It has used the standardized rating scales. The method of translation and back translation in Nepal language has been used. The authors have also done the pre-testing of questionnaire and calculation of Cronbach's afor internal consistency. The study sample has been taken from two different districts for better generalizability as compared to one geographical location. The mediation analysis adjusting for different socio-demographic variables, behavioral variables and educational variables was done. The major finding of the study is that the internet addiction statistically mediated indirect effect of sleep quality on depressive symptoms and sleep quality 
Table 1: Studies on Problematic Internet Use in Nepal

\begin{tabular}{|c|c|c|c|c|c|}
\hline SN & Authors & Sample & Sample character & Tools & Results \\
\hline 1 & $\begin{array}{l}\text { Pramanik et al., } \\
201226\end{array}$ & 130 & Medical students & $\begin{array}{l}\text { Young's Internet } \\
\text { Addiction Test }\end{array}$ & $\begin{array}{l}\text { 40\%-Mild } \\
\text { 41.53\%-Moderate } \\
\text { 3.07\%- Severe } \\
\text { Female preponderance }\end{array}$ \\
\hline 2 & $\begin{array}{l}\text { Marahatta, et } \\
\text { al.,201527 }\end{array}$ & 236 & $\begin{array}{l}\text { Health } \\
\text { students }\end{array}$ & $\begin{array}{l}\text { Young's Internet } \\
\text { Addiction Test }\end{array}$ & $\begin{array}{l}50.8 \% \text { - Mild } \\
40.7 \% \text {-Moderate } \\
1.3 \% \text { - Severe } \\
\end{array}$ \\
\hline 3 & Jha et al.,2016 28 & 452 & $\begin{array}{l}\text { Medical, dental, } \\
\text { nursing and allied } \\
\text { health science } \\
\text { students }\end{array}$ & $\begin{array}{l}\text { Self administered } \\
\text { questionnaire on } \\
\text { Facebook Use }\end{array}$ & $\begin{array}{l}\text { - } 98.2 \% \text { used Facebook } \\
\text { - Common adverse health } \\
\text { effects reported: } \\
21 \% \text { - Burning eyes } \\
19 \% \text { - Disturbed sleep } \\
\text { 16\% - Headache } \\
\text { - Reported both positive and } \\
\text { negative effects }\end{array}$ \\
\hline 4 & $\begin{array}{l}\text { Bhandari et al., } \\
2017^{29}\end{array}$ & 984 & $\begin{array}{l}27 \text { undergraduate } \\
\text { campuses }\end{array}$ & $\begin{array}{l}\text { Pittsburgh Sleep } \\
\text { Quality Index } \\
\text { Young's } \\
\text { InternetAddiction } \\
\text { Test Patient Health } \\
\text { Questionnaire-9 }\end{array}$ & $\begin{array}{l}\text { - Validated cutoff scores: } \\
\text { Poor sleep quality- } 35.4 \% \\
\text { Internet addiction -35.4\% } \\
\text { Depression- } 21.2 \% \\
\text { - Internet addiction } \\
\text { statistically mediated } 16.5 \% \\
\text { of the indirect effect of sleep } \\
\text { quality on depressive } \\
\text { symptoms } \\
\text { - Sleep quality statistically } \\
\text { mediated 30.9\% of the } \\
\text { indirect effect of internet } \\
\text { addiction on depressive } \\
\text { symptoms }\end{array}$ \\
\hline
\end{tabular}

statistically mediated the indirect effect of internet addiction on depressive symptoms. The implication of this finding is sleep quality and internet addiction should be assessed during counseling sessions for depressive symptoms among undergraduate students. All the studies that have been published from Nepal have pointed out the need of longitudinal research in this upcoming area of behavioral addiction.
Apart from this, at clinical level we have been getting cases of problematic internet use in our center, not as an addiction per se but as a comorbid condition with other mental disorders like OCD and personality disorders. It has also been seen as a part of behavioral problems in children. Hence considering this we emphasize on reporting of cases and studies in this area too. 


\section{CONCLUSION:}

There are few major issues like heterogeneity in scales used and cut off scores with the current research trend.Mere translation of the scales primarily developed in Western population may not be adequate to look at the socio-cultural perspectives of problematic internet use in Nepalese culture. From the clinical perspective there is no literature available on the clinical cases with problematic internet use. Now it is time for the Nepalese psychiatry to move ahead in the area of behavioral addiction in terms of awareness in the public and scientific literature. Once we can get a grip about the problem statement, clinical parameters, phenomenology, we can develop tailor made intervention strategies. Similarly, as a prevention strategies school and college based activities involving education and sensitization of the students as well as teachers, in order to detect the symptoms of Problematic Internet Use need to be carried out.

\section{REFERENCES:}

1. Number of Internet Users (2016) - Internet Live Statshttp://www.internetlivestats.com/internet-users/ (accessed 10 January 2017).

2. Lenhart A. Social Media \& Mobile Internet Use among Teens and Young Adults. Millennials. Pew Internet Am Life Projhttps://eric.ed.gov/?id=ED525056 (2010, accessed 4 January 2017).

3. Shaw M, Black DW. Internet addiction: definition, assessment, epidemiology and clinical management. CNS Drugs 2008; 22: 353-365.

4. Weinstein $A$, Lejoyeux $M$. Internet addiction or excessive internet use. Am J Drug Alcohol Abuse 2010; 36: 277-283.

5. Arlington VA, Association AP. Diagnostic and statistical manual of mental disorders. In: DSM. 2013, p. 1000.

6. Kuss D, Lopez-Fernandez $O$. Internet-use related addiction: The state of the art of clinical research. Eur Psychiatry 2016; 33, Supplement: S303.

7. Griffiths M. Internet Addiction - Time to be Taken Seriously? Addict Res 2000; 8: 413-418.

8. Shapira NA, Lessig MC, Goldsmith TD, et al. Problematic internet use: proposed classification and diagnostic criteria. Depress Anxiety 2003; 17: 207-216.

9. Bai YM, Lin CC, Chen JY. Internet addiction disorder among clients of a virtual clinic. PsychiatrServ Wash DC 2001; 52: 1397.

10. Beard KW, Wolf EM. Modification in the proposed diagnostic criteria for Internet addiction. CyberpsychologyBehav Impact Internet Multimed Virtual Real BehavSoc 2001; 4: 377-383.
11. Young KS, Rogers $R C$. The relationship between depression and Internet addiction. CyberpsycholBehav. Epub ahead of print 1998. DOI: 10.1089/cpb.1998.1.25.

12. Young KS. Psychology of computer use: XL. Addictive use of the Internet: a case that breaks the stereotype. Psychol Rep 1996; 79: 899-902.

13. Young KS. Internet addiction: The emergence of a new clinical disorder. CyberpsycholBehav. Epub ahead of print 1998. DOI: 10.1089/cpb.1998.1.237.

14. Grant JE, Potenza MN, Weinstein $A$, et al. Introduction to Behavioral Addictions. Am J Drug Alcohol Abuse 2010; 36: 233-241.

15. Davis RA. A cognitive-behavioral model of pathological Internet use. Comput Hum Behav. Epub ahead of print March 2001. DOI: 10.1016/S07475632(00)00041-8.

16. Chang MK, Man Law SP. Factor structure for Young's Internet Addiction Test: A confirmatory study. Comput Hum Behav 2008; 24: 2597-2619.

17. Moreno MA, Jelenchick L, Cox E, et al. Problematic Internet Use Among US Youth: A Systematic Review. Arch PediatrAdolesc Med 2011; 165: 797-805.

18. Greenfield DN. Psychological characteristics of compulsive internet use: a preliminary analysis. CyberpsychologyBehav Impact Internet Multimed Virtual Real BehavSoc 1999; 2: 403-412.

19. Pallanti S, Bernardi S, Quercioli L. The Shorter PROMIS Questionnaire and the Internet Addiction Scale in the assessment of multiple addictions in a high-school population: prevalence and related disability. CNS Spectr 2006; 11: 966-974.

20. Niemz K, Griffiths $M$, Banyard P. Prevalence of pathological Internet use among university students and correlations with self-esteem, the General Health Questionnaire (GHQ), and disinhibition. CyberpsychologyBehav Impact Internet Multimed Virtual Real BehavSoc 2005; 8: 562-570.

21. Christakis DA, Moreno MA. Trapped in the net: will internet addiction become a 21st-century epidemic? Arch PediatrAdolesc Med 2009; 163: 959-960.

22. Barkoviak M. China makes Internet addiction an official disorder. Dly Tech.

23. Mak K-K, Lai C-M, Watanabe H, et al. Epidemiology of internet behaviors and addiction among adolescents in six Asian countries. CyberpsychologyBehavSocNetw 2014; 17: 720-728.

24. Salehi M, NoroziKhalili M, Hojjat SK, et al. Prevalence of Internet Addiction and Associated Factors Among Medical Students From Mashhad, Iran in 2013. Iran Red Crescent Med J; 16. Epub ahead of print May 2014. DOI: 10.5812/ircmj.17256.

25. Hawi NS. Internet addiction among adolescents in Lebanon. Comput Hum Behav 2012; 28: 1044-1053.

26. Pramanik T, Sherpa MT, Shrestha $R$. Internet addiction in a group of medical students: a cross sectional study. Nepal Med Coll J NMCJ 2012; 14: 46-48.

27. Marahatta SB, Adhikari B, Aryal N, et al. Internet addiction and associated factors among health sciences 
students in Nepal. J Community Med Health Educ 2015; 5: 6-10.

28. Jha RK, Shah DK, Basnet S, et al. Facebook use and its effects on the life of health science students in a private medical college of Nepal. BMC Res Notes 2016; 9: 378.

29. Bhandari PM, Neupane D, Rijal S, et al. Sleep quality, internet addiction and depressive symptoms among undergraduate students in Nepal. BMC Psychiatry 2017; 17: 106 